\title{
A composite current detection control strategies of Active Power Filter
}

\author{
Zhou Miao, Xi Ziqiang, Liu leran \\ School of Electronic \& Electronical Engineering, Hubei University of Technology; Hubei \\ Collaborative Innovation Center for High-efficient Utilization of Solar Energy, Hubei University of \\ Technology, Wuhan, China
} zhoum2014@163.com, Xizq60@sina.com,2471819322@qq.com

Keywords: APF;current detection;harmonic compensation.

\begin{abstract}
The current is not specified a current in load side or network side at the detection of APF(active power filter) control. When the detection object is selected a different current, the compensation effect is different. This paper presents a simultaneous current detection control strategies which the network side and the load side current are detected at the same time. It was found the composite control mode full plays the advantages of the two control modes by comparing experiment, enabling harmonic compensation effect further improved.
\end{abstract}

\section{Introduction}

With the development of modern industry, the widely use of power electronic equipment cause the increasingly obvious negative impact on power quality. Until 1983, the instantaneous power theory was formally proposed by $\mathrm{H}$. Akagi to solve the problem of real-time detection of harmonic and reactive current. The rapid development and wide application of active power filter are in the treatment of harmonics. From the classic and basic principles of current harmonics and reactive power detection with parallel APF, the capacitor voltage of DC side and dual loop control perspective, the load harmonic and reactive current control strategies exist errors.

The literature [1] puts forward performance improvement of shunt active power filter with dual parallel topology, This paper describes the control and parallel operation of two APFs. Possible parallel operation situations of two APFs are investigated, and then the proposed topology is analyzed; the literature[2]joins the implementation of an indirect current control of a parallel hybrid filter (PHF) system with rectifier load to eliminate generated harmonics. The details of compensation principle, design, and PHF implementation are discussed. The proposed control enhances the performance of the passive filters (PFs) under unbalanced situations that are existing in the PFs under fault conditions. And a limited capacity of voltage source inverter, an upper limit for such compensation may be imposed by the proposed indirect current control. The literature [3] presents "Investigation of active damping approaches for PI-based current control of grid connected pulse width modulation converters with LCL filters,” This paper deals with various active damping approaches for PI-based current control of grid-connected pulse width-modulation (PWM) converters with LCL filters, which are based on one additional feedback. Filter capacitor current, as well as voltage feedback for the purpose of resonance damping, are analyzed and compared.However, the problem of fast dynamic tracking for the command signal changes still remains to be solve. The literature [4] is "Activity-Based Power Estimation and Characterization of DSP and Multiplier Blocks in FPGAs," It is an activity-based strategy for estimating the average power dissipation of hard DSP and multiplier blocks embedded in FPGAs.

The paper firstly will compensate the traditional active power filter feeder currents for the fundamental non-linear loads (positive sequence) active current as a compensation targets.The harmonic and reactive detection equivalent circuit model in traditional compensation strategies are established. And control strategy and the presence of errors are given. Then the paper proposes a simultaneous detection of network-side current and load current hybrid control strategy [5] [6] and shows the control strategy and principle of harmonic compensation. Finally from the experiment, 
the compound current detection control strategies can avoid errors caused by traditional detection algorithm and improve the compensation accuracy.

\section{The control strategy of the load current}

The APF's basic control strategy principle in the detection of the load current is: harmonics and reactive current $i_{L h}$ is detected in non-linear load current firstly. Then we can control APF to output a current $i_{c}$, which equals itand have opposite directions. Such supply current $i_{s}$ only contains the fundamental active component $i_{L f}$, which obtains the desired supply current and achieve the supply current harmonic suppression purposes. Using the formula can be described as:

$$
\begin{gathered}
i_{s}=i_{L}+i_{c} \\
i_{L}=i_{L f}+i_{L h}
\end{gathered}
$$

If we make

$$
i_{c}=-i_{L h}
$$

Then

$$
i_{s}=i_{L}+i_{c}=i_{L f}
$$

Figure 1 shows the equivalent circuit for access to high-pass filter after the shunt active power filter. In the figure, $u_{s}$ is for the network side voltage; $i_{s}$ is for the network side current; $R_{s}$ is for the equivalent resistance of resistance in network side and in shunt active power filter; and $L_{s}$ is for the equivalent inductance of in the network-side sense and in shunt active power filter; $C, L$ and $\mathrm{R}$ is for the composition of the high-pass filter; $i_{s n}+i_{L}$ is for load current and shunt active power filter currents, which can be seen as a current source.

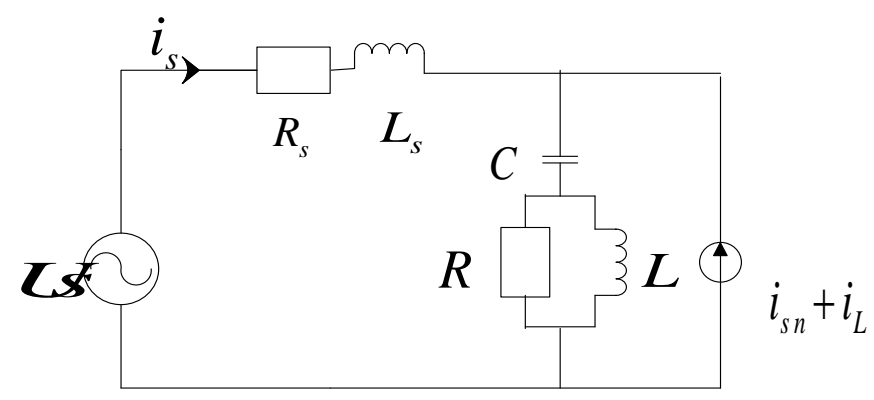

Figure 1 shunt active power filter equivalent circuit

The fluctuations of load current has a great relationship with power current switch in the main circuit. The power switch work-related high frequency harmonics will generate by turning off the power switch of the load current. Due to the high frequency of these harmonics, a high-pass filter can be added in parallel with the active power filter to filter out the higher harmonics. Resonance will be produced in the process of filtering out higher harmonics. This means that the load current harmonic is magnified by resonance. The network side of the current will include these harmonic components after the inflow of power. Therefore, the compensation effect is not very good in detecting the load current even if accessing high-pass filter.

Figure 2 shows the block diagram of the transfer function when the load current $i_{L}$ is selected to detect. The transfer function $G_{z}(s)$ is $i_{s n}+i_{L}$ to enter and $i_{s}$ to output in the figure. The transfer function $G_{L}(s)$ is for the current detection circuit. The transfer function $\mathrm{G}_{a}(s)$ is for controlling of the arithmetic processor. 


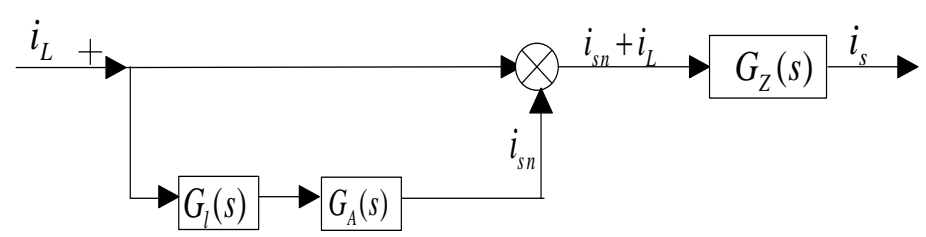

Figure 2 The transfer function block diagram detection control the load current in selected

From the control strategy, transfer function of the structure in the figure is open loop control when the load current is selected to detect. The transfer function is:

$w(s)=G_{Z}(s)\left[1+G_{L}(s)+G_{A}(s)\right]$

In traditional control strategy of active power filter, the detecting of the load side current is an open-loop control system, which there will always be a delay and error. Therefore the detection method will affect the accuracy of the active power filter compensation, further affecting the compensation quality of the active power filter.

\section{Compound control strategy in simultaneous detection of network-side and load current}

The simultaneous detection in network-side current $i_{s}$ and sensing load current $i_{L}$ is called a composite control. The control structure is shown in Figure 3.

The command current of composite control is from the load side. The purpose of detecting the current from the load side is mainly to compensate for harmonic current. The purpose of monitoring network side current is mainly inhibit resonance which may occur between the network side impedance and impedance PF.

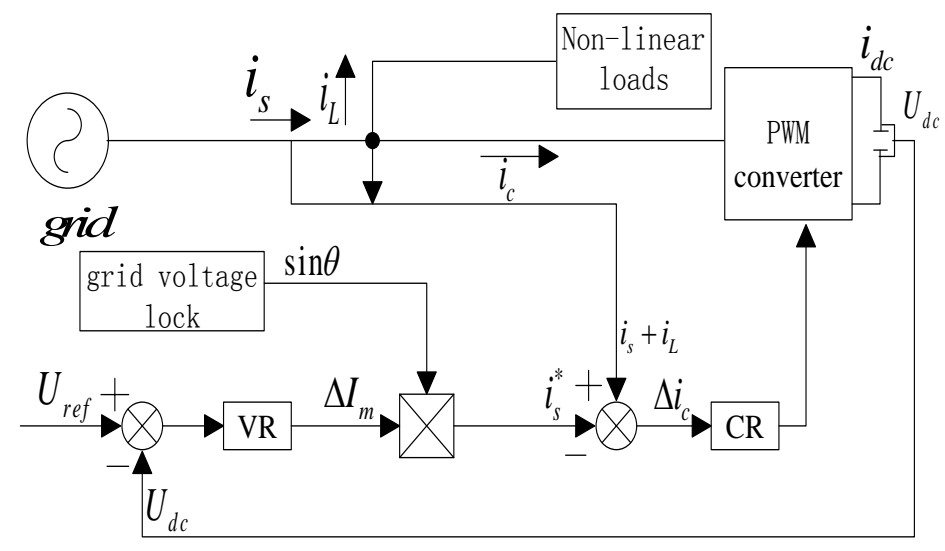

Figure 3 complex control schematics

The control block diagram is shown in Figure 4:

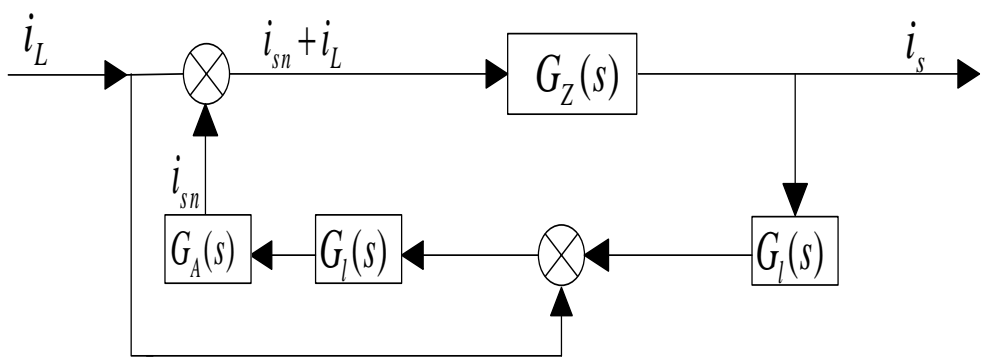

Figure 4 complex control structure of the transfer function

The transfer function $G_{z}(s)$ is $i_{s n}+i_{L}$ to enter and $i_{s}$ to output in the figure. The transfer function $G_{L}(s)$ is for the current detection circuit. The transfer function $G_{a}(s)$ is for controlling of 
the arithmetic processor. The transfer function $G_{F}(s)$ is for output current feedback loop transfer function. The transfer function is:

$$
w(s)=\frac{G_{Z}(s)\left[1+G_{A}(s)+G_{L}(s)\right]}{1-G_{F}(s) G_{Z}(s)}
$$

It can be seen that the composite current detection control method for the closed-loop transfer function of the function increase the output current feedback loop and the transfer function include in the closed loop, which makes the net current of harmonic compensated very close to a sine wave. On the other hand, the appropriate magnification selected can suppress resonance in Figure 2. Thereby the effect of compound control method for compensating can give the advantages of the two control modes.

\section{Results}

The PI double closed loop control strategy and SVPWM modulation are used through experimental prototype platform .And the composite control strategy of the simulation results are validated. Experimental parameters are as follows: (1)Power supply: 380V / 50Hz three-phase power supply, ignoring the line choke; (2) Load: three-phase rectifier bridge with a load electric wire, electric wire $20 \mathrm{~kW}$; (3) DC bus voltage is $850 \mathrm{~V}$; (4) capacitor in DC is C = 3300uF; (5) AC side output inductor $\mathrm{L}=4.5 \mathrm{mH}$ (subject to experimental conditions, the compensation can not reach the rated capacity, and therefore the output inductor is larger than the actual calculated value); (6) the system operating frequency is $12.8 \mathrm{kHz}$;

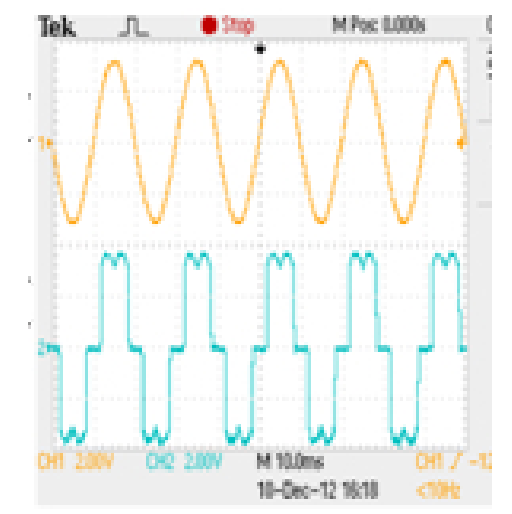

Fig.4 Uncompensated source current waveform

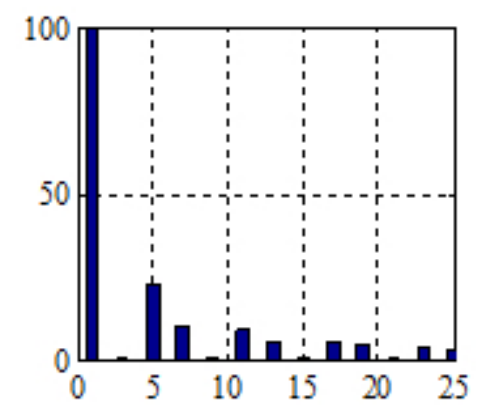

Fig.5 Uncompensated source current current spectrum 


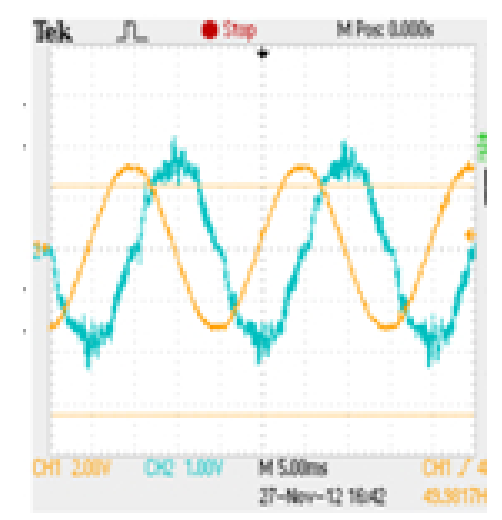

Fig.6 traditional compensation strategy source current waveform

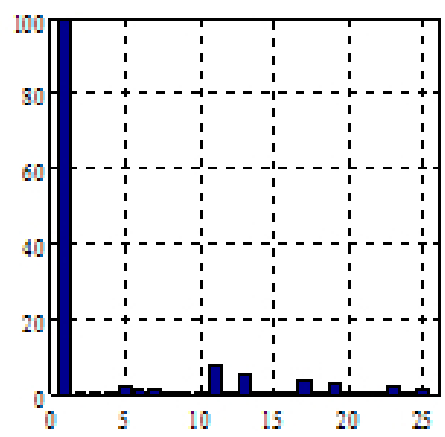

Fig.7 traditional compensation strategy source current spectrum

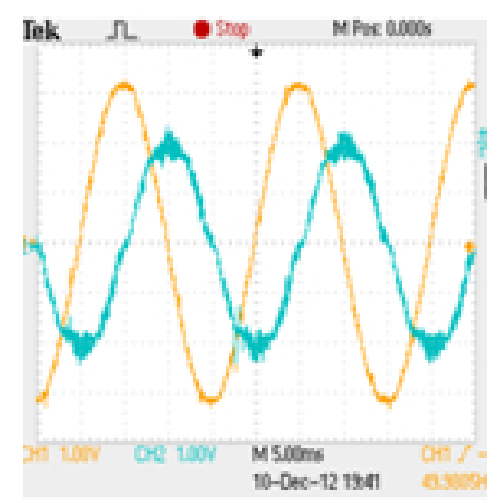

Fig.8 no harmonic detection compensation strategy source current waveform

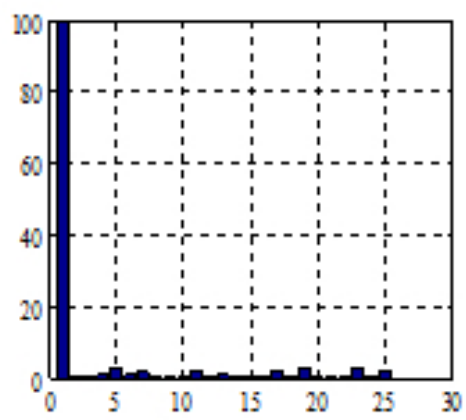

Fig.9 no harmonic detection compensation strategy source current spectrum

The grid side current waveform and current spectrum before the compensation is shown in Figure 4 and Figure 5. The grid-side current sensing current waveforms which use traditional compensation strategies and complex control strategies are shown from Figures 6 to 9. The results for the current total harmonic content of the source side decrease from 6.24 percent to 3.59 percent, 
which descripts that the complex current detection control strategy enables to improve accuracy of APF current compensation compared to traditional control strategy.

\section{Conclusions}

The current is not specified a current in load side or network side at the detection of APF control. When the detection object is selected a different current, the compensation effect is different. By detecting the load side current and the current complex current control which simultaneously detects the network side and the load side when the active power filter is controlled, the result is that recombination current detection control take full advantage of the two control modes, which enables harmonic compensation effect further improved.

\section{References}

[1] L. Asiminoaei, C. Lascu, F. Blaabjerg, "Performance improvement of shunt active power filter with dual parallel topology, " IEEE Transactions on Power Electronics, 2007, 22(1): 247-259.

[2] V. Verma, B. Singh, "Design and implementation of acurrent-controlled parallel hybrid power filter,” IEEE Transactions on Industry Applications, 2009, 45(5): 1910-1917.

[3] J. DANNEHL, F. FUCHS, S. HANSEN, "Investigation of active damping approaches for PIbased current control of grid connected pulse width modulation converters with LCL filters," IEEE Transactions on Industrial Application, 2010, 46(4): 1509-1517.

[4] N. Choy and S. J. Wilton, "Activity-Based Power Estimation and Characterization of DSP and Multiplier Blocks in FPGAs,” in Proc. IEEE Conf. FPT, 2006, pp. 253-256.

[5] WANG Guangzhu. The unnecessaries of harmonic and reactive current detection for active power filters_-Part I[J]. Transactions of China Electro Technical Society, 2007,22(1):137-141.

[6] Yi Hao, Zhuo Fang, Wang Xianwei, et al. Study of closed-loop control scheme for source current detection type active power filter [A]. IEEE ECCE [C]. 2010. 145-350. 